\title{
LAS ASOCIACIONES DE VECINOS ANTE EL PROCESO DEMOCRATICO ESPAÑOL: PERSPECTIVAS DE FUTURO
}

342.728: 352

$$
\text { por }
$$

\section{Javier-María Berriatúa San Sebastián}

Doctor en Derecho. Profesor de Derecho administrativo de la Universidad de Deusto

SUMARIO: I. INTRODUCCION--II. ORIGEN Y EVOLUCION DE LAS ASOCIACIONES DE VECINOS: 1. EL ORIGEN DE LAS ASOCIACIONES de Vecinos. 2. La eVolución de las Asociaciones de Vecinos.-III. LA IDENTIDAD DE LAS ASOCIACIONES DE VECINOS: 1. SU IDENTIFICACION NEGATIVA: A) Organismos ilegales. B) Organos de gobierno municipal. C) El movimiento ciudadano. 2. IDENTIFICACIÓN POSITIVA DE LAS ASOCIACIONES DE VECINOS.-IV. LAS ASOCIACIONES DE VECINOS Y LA POLITICA MUNICIPAL: 1. SU ANÁLISIS DESDE La PERSPECTIVA DE La ADMINISTRACIÓN PÚBliCa. 2. SU ANÁliSIS DESDE la PERSPECTIVA DE LOS PARTIDOS POLfTICOS. 3. EXAMEN DE LOS FACTORES DETERMINANTES. 4. TIPOLOGfa POLfTICA DE las Asociaciones de VeCINOS.-V. EL RETO DE LA INSTITUCIONALIZACION JURIDICA. VI. REFLEXION FINAL.

\section{INTRODUCCION}

No es exagerada en modo alguno la afirmación de que las Asociaciones de Vecinos, constituidas al amparo de la Ley de 24 de diciembre de 1964, constituyen uno de los fenómenos más importantes de la vida municipal española del siglo xx. De ahí que el asociacionismo vecinal haya acaparado la atención no sólo de la 
doctrina (1), sino también de la misma Administración pública, consciente de su importancia vital a la hora de investigar unos nuevos modelos jurídicos de gobierno suburbano (2).

El desarrollo del capitalismo de masas, con sus secuelas en déficit de equipamiento, unido al sentimiento, convertido ya en exigencia, de institucionalizar jurídicamente la participación directa del administrado en el gobierno de sus propios intereses vecinales, convierten a las Asociaciones de Vecinos en una de las piezas clave de la moderna organización municipal.

La importancia reseñada se ve acrecentada en España por la iniciación del proceso democrático.

Iniciado el proceso democrático, tras el largo período autoritario del Estado del 18 de julio, con el referéndum del 15 de diciembre de 1976, seguido con la autorización legal de los partidos políticos y las elecciones generales del 15 de junio de 1977, dicho proceso ha de completarse con la democratización del Municipio y la celebración en el mismo de elecciones municipales. Elecciones municipales libres, con pleno juego de los partidos políticos y en las que los vecinos y sus asociaciones vecinales puedan presentar

(1) Angulo, J.: Cuando los vecinos se unen, Madrid, 1972, y Por unos Ayuntamientos democráticos, Madrid, 1976; Asociación DE FAMILIAS DE RECALDEBERRI: El Libro negro de Recaldeberri, Barcelona, 1975. BERRIATÚa, J.: Las Asociaciones de Vecinos, Madrid, 1977. BorJa, J.: Qué son las Asociaciones de Vecinos, Barcelona, 1976. BorJA, J.; Tarrago, M., y BoIX, R.: Por una política municipal democrática, Barcelona, 1977. Castells, M.: Movimientos sociales urbanos, Madrid, 1974. CIDUR: Las Asociaciones de Vecinos en la encrucijada, Madrid, 1977; Madrid/Barrios, 1975, Madrid, 1976, y Movimiento de barrios y partidos politicos, Madrid, 1977. Garcfa FernANDEZ, J., y GonZÁlez, M. D.: Presente y futuro de las Asociaciones de Vecinos, Ma. drid, 1976. ОмеÑACA, J.: Movimiento ciudadano en crisis, Bilbao, 1977. ReBollo, RODRfGUEz y SOTOS: El movimiento ciudadano ante la democracia, Madrid, 1977. Villasante, T.: Los vecinos en la calle, Madrid, 1976. Villasante, T. y Murcia, A.: "Ayuntamientos democráticos y elecciones», en El Cárabo, 7 (1977), págs. 41-54. VIlloRIA, E.: Las asociaciones familiares, Ediciones del Movimiento, Madrid, 1971. Xifra Heras, J.: "Cauces de participación ciudadana en el planeamiento social de las Entidades locales», en $V$ Congreso Hispano-Luso-Americano-Filipino de Municipios, Madrid, 1970. Convergencia Reagrupamiento Abertzale Socialista: Sobre movimiento popular, sin lugar ni fecha. En cuanto a números monográficos de revistas, pueden consultarse los siguientes: Papers, Revista de Sociología, núm. 3, 1974. Espaces et Sociétés, núms. 6-7, 1972. Documentación Social, núm. 8, 1972, y número 19, 1975. Cuadernos 'para el Diálogo, extraordinario, núm. XIX, 1975. Teoría y Práctica, núm. 5, 1977.

(2) El interés por esta problemática indujo al Instituto de Estudios de Administración Local a celebrar en Logroño, los días 10 al 12 de febrero de 1977, un Seminario de Investigación sobre «Desarrollo comunitario urbano: especial referencia a distritos y barrios». La importancia de las Asociaciones de Vecinos en el tema investigado es indudable. El mismo interés aparece en el artículo, premiado en el concurso sobre «Reforma política y administrativa en la España actual», de LLISET BORRELl, F.: «Incidencia de la reforma política en la Administración pública», en Documentación Administrativa, 172 (1976), págs. 7-29. 
y elegir, sin limitación alguna, a sus representantes municipales.

En este marco de renacimiento democrático, el futuro de las Asociaciones de Vecinos aparece, en principio, lleno de fuerza y esperanza. Solucionados viejos problemas pendientes, las Asociaciones de Vecinos "en trámite» habrán de entrar, cogidos de la mano de la democracia, en el pleno juego de la nueva legalidad, y serían los nuevos aires de la democracia los que habrían de llenar a las Asociaciones de Vecinos de posibilidades sin fin. Posibilidades, desconocidas hasta la fecha, de nuevos medios de convocatoria, reunión, expresión y acción de masas. Ampliado el horizonte de la legalidad y las posibilidades reales de actuación de las Asociaciones de Vecinos y subsistiendo intactos los graves problemas de la ciudad postindustrial, el porvenir y el futuro pujante de las Asociaciones de Vecinos no debería ofrecer duda alguna. Con la democracia, en pura racionalidad al menos, se iniciaría así una nueva etapa. Las Asociaciones de Vecinos entrarían en la plenitud de su mayoría de edad.

Sin embargo, sentimos discrepar de tanto idílico futuro. Creemos que el nacimiento tardío a la vida democrática puede suponer para las Asociaciones de Vecinos una utilización instrumental de las mismas por los partidos políticos y un vaciamiento de competencias si se institucionaliza jurídicamente la participación del vecindario en el gobierno de su distrito o barrio. Peligros ambos que cuestionan la identidad misma de las Asociaciones de Vecinos. No creemos aventurado afirmar que existen posibilidades reales de asistir a la iniciación de un proceso de extinción de las Asociaciones de Vecinos. Extinción por inanición. Por fosilización. Por conversión en entes que, si bien subsisten como tales entes en el mundo del Derecho, han perdido su fuerza social y la razón de su existencia. Entes caducos que pasarán a la historia de la sociología urbana y de la vida municipal española como una ocasión perdida al ser devorados prematuramente por las organizaciones políticas de la nueva democracia y de su Administración municipal.

La hipótesis formulada nos obliga a examinar la doble vertiente de las Asociaciones de Vecinos con sus respectivos riesgos de utililización instrumental y de vaciamiento funcional por parte de los partidos políticos y de la propia Administración pública. Examen que iniciamos con el estudio de una cuestión previa: la identidad de las Asociaciones de Vecinos y las variaciones que las mismas han sufrido desde el origen de esta figura vecinal. 
Nuestro punto de partida no es un mero capricho literario. Desde el origen de las Asociaciones de Vecinos éstas han sufrido una adherencia de elementos políticos extraños, que han difuminado la naturaleza propia de las Asociaciones de Vecinos, enrareciendo sus relaciones, tanto con los partidos políticos como con la misma Administración pública. Se impone, pues, como necesidad previa, la clarificación de la figura que investigamos. Clarificación que realizaremos examinando el origen y evolución de las Asociaciones de Vecinos para pasar después a fijar su identidad. Llegados a este punto, estaremos en condiciones de investigar los efectos que, tanto los partidos políticos como la institucionalización jurídica de la participación del vecindario en el gobierno suburbano, pueden suponer para la vida y el futuro de las Asociaciones de Vecinos.

\section{ORIGEN Y EVOLUCION DE LAS ASOCIACIONES DE VECINOS}

\section{El origen de las Asociaciones de Vecinos}

Nacidas las Asociaciones de Vecinos para solucionar déficits de equipamientos e infraestructuras de la ciudad industrial capitalista (3), es indudable que las causas estructurales de aparición de las Asociaciones de Vecinos estriban en la organización capitalista de la ciudad industrial y en las contradicciones propias de dicho sistema (4). Pero más que señalar las causas estructurales originantes de las Asociaciones de Vecinos interesa poner de relieve las causas inmediatas de estas Asociaciones en España y encaminar las repercusiones que la apertura democrática puede suponer en la vida actual de las Asociaciones de Vecinos.

Constatamos, en efecto, que, junto a la necesidad de solucionar los déficits de equipamientos colectivos, causa originante por excelencia de este tipo de asociaciones, las Asociaciones de Vecinos han

(3) La problemática relativa a las posibles contradicciones urbanas existentes en las ciudades socialistas es un tema de gran interés, si bien no suficientemente investigado. Ello, no obtasnte, cae fuera del campo que analizamos, por lo que ilos limitamos a examinar el origen de las Asociaciones de Vecinos en el Estado español.

(4) CaSTELls, M.: La cuestión urbana, Madrid, 1974, y Movimientos sociales urbanos, Madrid, 1974. CAPEL, H.: Capitalismo y morfología urbana, Barcelona, 1975. Circulo de Economfa: Gestión o caos: el Area Metropolitana de Barcelona, Madrid, 1973. BORJA, J.; TARRAGo, M., y BoIX, R.: Por una política democrática, Barcelona, 1977, págs. 26-27. 
debido su nacimiento inmediato en numerosos casos a motivos puramente circunstanciales, cuando no a la necesidad de crear una plataforma de actuación en una época en que las libertades públicas de asociación, reunión y expresión eran sumamente limitadas (5). Surge, así, un vicio, o al menos un elemento debilitante de la vitalidad de las Asociaciones de Vecinos cuando éstas, advenidas a las nuevas posibilidades legales de la democracia, se encuentran con ;que el motivo circunstancial por el que nacieron ha desaparecido y es necesario asumir unos fines que no existieron o que no son sentidos como primordiales por el vecindario.

Juntamente con este dato de discordancia entre el motivo originante y la finalidad actual a perseguir por las Asociaciones de Vecinos, hemos de reseñar un segundo aspecto que consideramos de importancia. Es curioso observar la diferencia existente entre la realidad francesa o italiana y la española en orden a la actualidad de los partidos políticos. En Francia e Italia, señala Lefebvre (6), una de las causas originantes del nacimiento de las Asociaciones de Vecinos es, sin duda alguna, el desinterés de los partidos políticos por los problemas que, a nivel local, se presentan en las barriadas o distritos urbanos, así como el recelo ante una democracia directa difícilmente controlable por el burocratismo actual de las organizaciones políticas. Este factor determinante es desconocido en el proceso histórico del nacimiento de las Asociaciones de Vecinos en España. Las relaciones entre partido político y Asociación de Vecinos, en el período de nacimiento de estas últimas, no aparece como una relación causal. La clandestinidad de las organizaciones políticas, dada la prohibición legal de los partidos políticos, impidió a estas organizaciones el funcionar a la luz del día. De ahí que la problemática francesa o italiana sea desconocida en España eń la época de creación de las Asociaciones de Vecinos. Problemática que, sin embargo, tiene su importancia en la actualidad, cuando abierto el proceso democrático la lucha entre las Asociaciones de Vecinos y los partidos por el predominio del poder vecinal empieza a verse en más de un caso. En la España del presente las relaciones

(5) Berriatúa, J.: Las Asociaciones de Vecinos, Madrid, 1977, pág. 201. BoRJA, J.: Qué son las Asociaciones de Vecinos, Barcelona, 1977, págs. 36-37. CIDUR: Madrid/Barrios 1975, Madrid, 1976, págs. 19-22. EQUIPOS DE BASE: «San Jorge ante la ilegalidad y la especulación», en Teoria y Práctica, 5 (1977), pág. 65. BustamanTE, E.: «La ciudad es nuestran, en Cuadernos para el Dialogo, 240 (1977), págs. 38-42.

(6) PUIG DE LA Bellacasa, J. M.: aLos conflictos entre clases se plasman en la estructura urbana. Entrevista a Henri Lefebvre», en Hechos y Dichos, 448 (1974), página 43. 
Asociación de Vecinos-partido político aparecen, pues, no como unas relaciones de causa a efecto, sino como resultado de una situación de hecho existente y que de día en día, según veremos, va tomando aspectos sutilmente conflictivos.

La problemática que actualmente aflora sobre el origen de las Asociaciones de Vecinos es un dato que debemos retener en la investigación que estamos realizando sobre las Asociaciones de Vecinos ante el proceso democrático. Pero, además, queremos llamar la atención sobre un segundo aspecto. Nos referimos a la evolución histórica sufrida por algunas Asociaciones de Vecinos, las cuales, de forma silenciosa y recogiendo sentimientos profundamente sentidos por algunos vecindarios, han ido ampliando sus fines sociales hacia campos de actuación de claro contenido político. Veamos el proceso.

\section{LA EVOLUCí́N DE LAS ASOCIACIONES DE VeciNos}

La dinámica propia de estas asociaciones ha supuesto para muchas de ellas una evolución hacia formas de actuación mucho más políticas, pero dentro siempre del ámbito propio de los fines sociales de las Asociaciones de Vecinos. La naturaleza misma de los mecanismos de decisión del poder municipal ha inducido a las Asociaciones de Vecinos a ampliar sus formas de actuación, pasando de una mera reivindicación en la planificación de su unidad vecinal, para terminar con la exigencia de participación en el gobierno municipal y en la necesidad de un cambio estructural que democratice el vigente sistema municipal. En esta misma línea hemos de señalar la creación de las Federaciones de Asociaciones de Vecinos en Madrid, Barcelona y Bilbao, que, recogiendo las necesidades vecinales a nivel total del Municipio, unificando criterios de actuación y respuesta, se presentan como una fuerza que, si bien a tenor literal de sus estatutos es puramente reivindicativa, en la praxis de sus convocatorias de masas aparece como un poder político paralelo, cuando no antagónico, al instituido legalmente. Evolución que culmina con la labor de concienciación política seguida de cara a sus asociados y al vecindario en general por numerosas Asociaciones de Vecinos, denunciando las causas originantes del deterioro urbano y proponiendo como solución única la transformación del sistema capitalista en otro cualitativamente distinto, el socialista, solu- 
ción única, a su juicio, de los problemas urbanos de las barriadas populares.

Los últimos estados de esta evolución presentarán, según veremos, dificultades de calificación legal. Pero de momento interesa. señalar un nuevo aspecto de esta línea evolutiva. Nos referimos a la. asunción por parte de las Asociaciones de Vecinos de reivindicaciones que, al socaire de ser sentidas por el vecino, suponen una extralimitación de fines, y que de repetirse insistentemente pueden suponer una desnaturalización de las Asociaciones de Vecinos y la iniciación de un proceso que, a medio o largo plazo, puede suponer la extinción misma de estas asociaciones.

La limpieza de fines urbanos y la legalidad de los medios a emplear son, a nuestro juicio, dos aspectos de la máxima importancia de cara a la subsistencia misma de las Asociaciones de Vecinos como asociaciones de defensa de intereses. El olvidarlo puede ser un gran error. La avaricia de algunos líderes de capitalizar a corto piazo el capital político de las Asociaciones de Vecinos y de utilizarlas para finalidades distintas de la defensa de intereses vecinales puede ser un bello sueño que termine con el abandono de las asociaciones por los vecinos, los cuales, al hacerse socios de estas instituciones, han exigido, y creemos que seguirán haciéndolo, una limpieza de actuación que excluya la manipulación política y una legalidad de medios que les ponga al amparo de toda posible represión por parte de las fuerzas de orden público.

En esta línea evolutiva enmarcamos no sólo las transgresiones manifiestas en medios y fines realizadas por algunas Asociaciones de Vecinos (7), sino también la integración de las Asociaciones de Vecinos en el movimiento ciudadano y la asunción por estas asociaciones vecinales de las finalidades políticas de dicho movimiento. Finalidades complejas, de naturaleza múltiple (cultural, juvenil, comercial, etc.), que desbordan el estrecho límite de interés vecinal para abarcar un amplio abanico de intereses de la pequeña y mediana burguesía. Finalidades y convocatoria de masas empleadas para su consecución que hay que encuadrarlas en las opciones

(7) Véanse las actuaciones de las Asociaciones de Familias del Gran Bilbao de principios de 1976 -BerRiatúa, J.: o. c., pág. 229, nota 302-, así como ciertas Asociaciones de Vecinos de Guipúzcoa, asumiendo el llamamiento de la marcha por la libertad de Euzkadi o la libertad del líder etista Apalategui y el llamamiento que las Asociaciones de Vecinos hicieron a nivel general del Estado español pidiendo la amnistía y la democratización política del pais. 
y estrategias políticas concretas que determinados partidos sostienen frente al actual sistema capitalista de nuestras ciudades.

Las características de nacimiento de algunas asociaciones, así como la evolución reseñada, nos ponen de relieve la necesidad de delimitar el contenido político o no de las Asociaciones de Vecinos y sus relaciones con los partidos. Problemática que abordamos con el análisis previo de la identidad de las Asociaciones de Vecinos. Fijada la misma, estaremos en condiciones de investigar las relaciones Asociaciones de Vecinos-partidos políticos, y las repercusiones que para las mismas puede suponer la institucionalización juridica de la participación popular en el gobierno municipal.

\section{II. LA IDENTIDAD DE LAS ASOCIACIONES DE VECINOS}

Comenzamos el proceso de identificación de las Asociaciones de Vecinos determinando lo que, a nuestro juicio, no son. Metodología negativa de investigación que seguimos por sus indudables resultados prácticos de clarificación.

\section{SU IDENTIFICACIÓN NEGATIVA}

Entendemos que las Asociaciones de Vecinos no son:

\section{A) Organismos ilegales}

La ilegalidad es una de las notas que debemos excluir de las Asociaciones de Vecinos desde el inicio de nuestra reflexión. La ilegalidad de medios y fines, tanto próximos como últimos, debe ser totalmente excluida. Esta afirmación no es óbice para que podamos constatar ciertas actuaciones ilegales por algunas Asociaciones de Vecinos (ocupación de viviendas, de zonas verdes, manifestaciones no autorizadas, etc.). La posibilidad del ilícito jurídico es una posibilidad real de facto que no excluye la tesis sostenida sobre la legalidad de las Asociaciones de Vecinos. Legalidad exigida por la Ley de 24 de diciembre de 1964 y cuya inobservancia dará lugar a las sanciones determinadas en dicha Ley y entre las que se contempla la disolución misma de la asociación. En último término, asistimos a un proceso dialéctico legalidad-ilegalidad con arreglo al 
cual las Asociaciones de Vecinos, reconociendo explícitamente su carácter legalista en fines y medios y rechazando el empleo sistemático del enfrentamiento a la normativa vigente, han de responder a las exigencias de sus bases de afiliados y dar respuesta a situaciones de injusticia material manifiesta utilizando los métodos necesarios, aunque en ocasiones sean ilegales.

Desde el punto de vista sociológico, entendemos que la nota definitoria de la legalidad es esencial para la existencia propia de este tipo de asociaciones y que su abandono y la aceptación de la ilegalidad o de la mera «a-legalidad» daría lugar a otro movimiento social urbano cualitativamente distinto (8).

Pero no sólo desde el punto de vista sociológico estimamos como componente esencial de las Asociaciones de Vecinos el dato de la legalidad, sino que desde un ángulo jurídico la legalidad se convierte, además, en condición de posibilidad de la existencia misma de estas Asociaciones.

Esta afirmación arrastra consigo una importante consecuencia: el carácter meramente reformista de las Asociaciones de Vecinos (9). Guste o no guste, el reconocimiento legal de las Asociaciones de Vecinos como personas jurídicas, supone el sometimiento de las mismas a la ley. Y este sometimiento supone el abandono del carácter revolucionario por parte de las Asociaciones de Vecinos. Estas se comprometen a la aceptación de la legalidad vigente y al empleo de los medios legales que el ordenamiento jurídico vigente en el país permita utilizar. Y ello no sólo en las reivindicaciones y acciones concretas de actuación, sino también, y ello es más importante a nuestro juicio, en los medios de carácter reformista y por la vía legal a emplear cuando lo pretendido es la sustitución de un sistema capitalista urbano por otro socialista. La legalidad de medios y fines supone para una Asociación de Vecinos que pretenda tal sustitución el empleo de la vía legal de acceso al socialismo. Vía legal, con sus antecedentes chilenos y de izquierda europea, que supone una raya divisoria neta y totalmente distinta de la línea de ruptura y de lucha de clases a nivel urbano propugnada por las organizaciones de la izquierda revolucionaria.

La Asociación de Vecinos, así lo creemos, en el supuesto de que adopte un planteamiento socialista de la vida urbana, se ve cons-

(8) Vid. Berriatúa, J.: o. c., págs. 70 a 76 y 119 a 121.

(9) Vid. Berriatúa, J.: Ibidem, y Tenorio, P.: aPersonalidad juridica y sindicato», en Revista de Trabajo, 38 (1972), págs. 83-125. 
treñida a utilizar como modo ordinario y propio de actuación los medios legales admitidos por la legislación del país para la manifestación de ideas y movilización de masas, así como al uso de la vía parlamentaria si desea obtener cualquier modificación legal, incluida la abolición del capitalismo (10). Esta es la cruz y el principio vital de las Asociaciones de Vecinos.

\section{B) Organos de gobierno municipal}

Tampoco son órganos de gobierno municipal. En nuestro ordenamiento jurídico, el barrio no es ningún ente territorial, ni la Asociación de Vecinos es órgano alguno de Administración local a nivel inframunicipal. Afirmación que encierra dos consecuencias de interés.

De una parte, y de cara a la institucionalización jurídica de la participación del vecindario en el gobierno de su unidad vecinal, las Asociaciones de Vecinos no son actualmente, y creemos que tampoco lo serán en el futuro, ningún órgano de gobierno suburbano. Son entes intermedios entre la sociedad y el Municipio, entre el vecino y la Administración pública. Entes con derecho a vigilar, controlar y cooperar con la Administración pública, pero distinta a ésta. Su naturaleza específica de asociación de defensa del interés vecinal frente a la Administración, deberá llevar a éstas a estar atentas a las necesidades urbanas de sus asociados y de su ámbito vecinal de actuación y a defender estos intereses frente a la Administración. Defensa que puede y debe ser reconocida legalmente e institucionalizada jurídicamente a través de mecanismos de colaboración. En este sentido, los ejemplos existentes en el País Vascu sobre la participación de las Asociaciones de Vecinos en el

(10) A la luz de lo expuesto pueden observarse las profundas diferencias que separan a las Asociaciones de Vecinos de algunas organizaciones de la izquierda revolucionaria. A título de muestra señalamos las siguientes: 1. Los "Comités de lutte de mal-logés», de la Renault, en Francia - vid. XXX: «Logement et lutte de classes. Compte rendu d'une pratique militante de quartier», en Espaces et So. ciétés, núms. 6-7 (1972), págs. 59-88- 2. La Asamblea del Pueblo, propugnada en la «Alternativa de E. I. A. de régimen transitorio hacia el Estatuto de Autonomían, Bilbao, 8 de septiembre de 1977, a cuyo tenor: «La Asamblea del Pueblo estará formada por cuantos cargos municipales quieran integrarla más los organismos populares existentes en cada Municipio - Asociaciones de Vecinos, Gestoras proamnistía, Gestoras pro-estatuto, etc.- $\rightarrow$. Es un organismo extralegal y no reglamentado, ya que unas veces exigirá el cumplimiento de la legalidad y otras la modificación de una legalidad antidemocrática. Es, en definitiva, la instancia suprema de la presión popular vasca. 
control provisional de los Ayuntamientos, puede ser una fórmula a tener en cuenta no sólo como fórmula transitoria, sino permanente. Pero, insistimos, incluso en estos casos la Asociación de Vecinos no es un órgano de gobierno municipal, sino que sigue siendo una asociación privada distinta de la Administración pública. Así, la representatividad del vecindario se sigue realizando a través de la elección de concejales y los órganos del Municipio siguen siendo los fijados en la Ley de Régimen local. Con ellos colaboran las Asociaciones de Vecinos, pero su actividad se limita a eso, a la simple colaboración. Colaboración que no supone ningún milagro de metamorfosis. Las Asociaciones de Vecinos no se transforman en órganos del Municipio, ni devienen, por ende, en Administración pública. Siguen siendo lo que son: asociaciones de Derecho privado.

Este carácter privado de la Asociación de Vecinos y su neta separación de la Administración pública debe tenerse en cuenta en orden a posibles reorganizaciones legales del distrito o barrio. No creemos que es un mero olvido, sino la consagración de una técnica más depurada, el hecho de que la Ley italiana de 18 de abril de 1976 base, según veremos, la organización municipal a nivel suburbano, no en las Asociaciones de Vecinos, sino en el Consejo de Barrio.

Si de cara a la Administración pública son asociaciones privadas que colaboran con aquélla, a través de un deseable reconocimiento legal de sus facultades de vigilancia, control e información, pero sin que el reconocimiento legal de dichas facultades las convierta en órganos administrativos del ente local, desde otro ángulo distinto, de cara al pueblo o vecindario, las Asociaciones de Vecinos tampoco son la organización legalizada del poder popular.

Nos detenemos a examinar esta afirmación tan profundamente sentida, tanto por algunos vecinos como por ciertas organizaciones políticas de la izquierda revolucionaria. Ya desde el nacimiento de las Asociaciones de Vecinos en 1964, pudimos observar en ciertos lideres vecinales el sentimiento oculto de que lo realmente importante en la vida vecinal es la toma del poder de la ciudad por el pueblo. Pueblo, en aquel entonces, emigrante, de reciente arribada. Pueblo arrinconado en los barrios periféricos, con conciencia incipiente de explotación urbana. El sentimiento de esta condición de explotación se manifestaba en el deseo espontáneo de la toma del poder vecinal en sus barriadas, viendo en las Asociaciones de Vecinos la organización idónea para conseguirlo. 
Este sentimiento espontáneo se ha convertido hoy en reflejo y en punto central ideológico de ciertas alternativas democráticas de la izquierda revolucionaria urbana. Nos referimos a todas aquellas organizaciones asamblearias, basadas en la asamblea de pueblo o barrio como órgano de poder popular y de autogestión municipal. Pues bien, el asambleísmo popular, en sus diversas formas (11), podrá ser la institución ideológica y el instrumento táctico de poder popular a nivel de barrio o pueblo defendido por la izquierda revolucionaria, pero sus diferencias con la Asociación de Vecinos son manifiestas:

1. La Asociación de Vecinos es fundamentalmente un sindicato vecinal. La asamblea es el órgano y la manifestación del poder popular como contrapoder político del vigente sistema capitalista urbano.

2. La asamblea supone una forma de democracia directa no sólo en cuanto a la manifestación de la voluntad del pueblo en dicha asamblea, sino también en cuanto que la misma es el supremo poder de decisión a nivel de barriada o pueblo. Poder de decisión del que carecen las Asociaciones de Vecinos.

3. La asamblea podrá comprender, en la mentalidad de algunas ideologías, solamente a las Asociaciones de Vecinos existentes en el barrio o pueblo, identificando así la asamblea con la Asociación de Vecinos, desnaturalizando su finalidad y utilizando instrumentalmente a éstas. Pero para la mayoría de los planteamientos de la izquierda, la asamblea es distinta de la Asociación de Vecinos, comprendiendo al vecindario entero - no sólo a los afiliados a la asociación- y a todas las instituciones revolucionarias existentes en el mismo.

4. El asambleísmo rechaza la vía electoral o, si la admite, supedita en todo caso la actuación de los representantes municipales

(11) Basados en el poder popular como titular de la soberanía urbana y en el asambleísta de barrio o pueblo como instrumento de expansión de dicho poder, incluimos: 1. La alternativa anarquista. 2. La alternativa E. I. A. con la Asamblea del Pueblo como órgano supremo y exclusivo. 3. La alternativa de EHAS, que subordina los concejales legalmente elegidos a la voluntad de la Asamblea del Pueblo o Barrio. 4. Los que en la Asamblea del Pueblo incluyen a todas las organiza. ciones vecinales o sólo a algunas de ellas. 5. Los que identifican a las Asociaciones de Vecinos con la voluntad popular. En este sentido, Eouipos DE BASE. BarCELONA: «Los barrios y el poder popular», en Teoría y Práctica, 5 (1977), pág. 50. Așimismo, OMEÑACA, J.: Movimiento ciudadano en crisis, Bilbao, 1977, págs. 116-117; y Villasante, T., y MURCia, A.: «Ayuntamientos democráticos y elecciones», en $E l$ Járabo, 7 (1977), págs. 52-53. 
elegidos a la voluntad y decisiones de la asamblea popular. La Asociación de Vecinos, por el contrario, admite la vía electorista y, cualquiera que sea el resultado de una elección municipal, su función y reivindicación urbana y de colaboración, conflictiva o no, con la Administración pública seguirá teniendo sentido.

$5^{\circ} \quad$ La institucionalización jurídica de las relaciones entre las Asociaciones de Vecinos y la Administración pública se realiza a través de las técnicas de colaboración Administración-administrado. La institucionalización de la asamblea de barrio o pueblo supondría la generalización a escala urbana del Concejo abierto, como órgano de democracia directa a nivel suburbano.

6. La Asociación de Vecinos es una asociación de carácter legalista, según hemos visto. La asamblea utilizará la legalidad como medio de acción, pero sin subordinarse a ella. En último término, el asambleísmo supone una forma superior de lucha contra el capitalismo urbano que la meramente legalista empleada por las Asociaciones de Vecinos.

7. La Asociación de Vecinos no tiene por qué cuestionar «necesariamente» el sistema urbano vigente, así podemos apreciarlo en las antiguas Asociaciones de Cabezas de Familia incardinadas en el desaparecido Movimiento Nacional. La asamblea, por el contrario, cuestiona tanto el sistema capitalista urbano como la superestructura legal de los órganos de gobierno municipal.

Las diferencias reseñadas impiden identificar a las Asociaciones de Vecinos con la voluntad política del pueblo a nivel de barrio. Esta voluntad popular se manifiesta, legalmente, en la elección de sus representantes por medio de las correspondientes elecciones municipales, y a nivel extralegal en el contrapoder de una asamblea de barrio o pueblo. Pero nunca en una Asociación de Vecinos, organización nacida básicamente para la reivindicación urbana y cuyas máximas competencias alcanzarán, como mucho, las meras facultades de información, vigilancia, propuesta y control de la Administración.

\section{C) El movimiento ciudadano}

Por último, las Asociaciones de Vecinos tampoco son el movimiento ciudadano. En este sentido coincidimos plenamente con OMEÑACA cuando afirma que «el movimiento ciudadano no hay que 
identificarlo sólo y exclusivamente con las Asociaciones de Vecinos o de Familias. Los centros culturales, los clubs juveniles, las Asociaciones de Padres de Alumnos, las peñas deportivas, las comisiones de fiestas, los clubs de danzas, las Asociaciones de Amas de Casa, etc., son entidades y grupos enraizados en el barrio o pueblo y que tienen un mismo carácter de gestión popular». Estas entidades, a las que en ocasiones hay que sumar las Asociaciones de Comerciantes, de Propietarios Urbanos, los Amigos de la Ciudad, los movimientos feministas o los Colegios profesionales de Arquitectos, constituyen el movimiento ciudadano, dentro del cual se incluyen las Asociaciones de Vecinos, pero sin que se identifiquen con él. No puede confundirse el todo con la parte, aunque ésta sea la más importante.

La importancia de la distinción reseñada no es de mera lógica formal. Arrastra consigo importantes consecuencias de orden material, si tenemos en cuenta los conflictos e intereses encerrados en la misma. En este sentido, y en atención a la conflictualidad urbana, Jordi BORJA, Marcal TARRAGo y Ricard BoIX señalan cómo en los barrios han coincidido diferentes tipos de conflictos que han dado lugar a movimientos sociales urbanos diferentes. Así, y siguiendo la terminología de dichos autores, distinguimos entre: «a) los que denominamos estrictamente "urbanos", es decir, que hacen referencia a la vivienda, condiciones urbanísticas de la zona, servicios colectivos (escuelas, transportes, sanidad, etc.). Son, en su mayoría, típicamente reivindicativos. b) Los movimientos sociales que, si bien se refieren también a las condiciones de vida (reproducción de la fuerza de trabajo), no son específicamente urbanos. Nos referimos a los que se refieren, por ejemplo, a los precios, al paro...c) Los movimientos laborales encuentran también en los barrios bases de apoyo, bien porque las empresas en conflicto están en la zona o porque en el barrio viven trabajadores participantes en la lucha. $d$ ) Los medios culturales y de vida social colectiva se incorporan a las necesidades fundamentales de la población y su reivindicación es una nueva dimensión de los movimientos urba. nos» (12).

Por razón, pues, de la conflictualidad no conviene olvidar que el conflicto estrictamente urbano, propio del campo de las Asociaciones de Vecinos, es distinto de los no específicamente urbanos,

(12) Borja, J.; TARrago, M., y BoIx, R.: Por una politica municipal democratica, Barcelona, 1977, pág. 79. 
bien hagan éstos referencia a las condiciones generales de vida o a las relaciones laborales o culturales.

Juntamente con el dato de la conflictualidad señalamos también cómo los intereses del movimiento ciudadano son, en ocasiones, más amplios que los estrictamente vecinales, propios de las Asociaciones de Vecinos. En este sentido, entendemos que el movimiento ciudadano supone un conglomerado heterogéneo de intereses diversos, a veces coincidentes, de difícil enumeración, pero en todo caso diferentes de los meramente vecinales. Las Asociaciones de Comerciantes, de Propietarios Urbanos, los movimientos ecologistas, los Amigos de la Ciudad y no digamos nada de los Colegios profesionales como el de Arquitectos, comprenden capas sociológicas de burguesía distintas de las populares residentes en la generalidad de los barrios en los que actúa una Asociación de Vecinos, y responden a intereses basados en la prosperidad, el comercio, la estética o la profesión. Intereses que, siendo dignos de todo respeto, son, sin embargo, de naturaleza distinta a la del interés vecinal propio de las Asociaciones de Vecinos.

El hecho de que los conflictos e intereses defendidos por las Asociaciones de Vecinos sean de naturaleza diversa al resto de las asociaciones y entidades encuadradas en el movimiento ciudadano adquiere relieve, a los efectos de nuestra reflexión, cuando el movimiento ciudadano tiende a absorber dentro de sí, de sus reivindicaciones y de su estrategia política a las Asociaciones de Vecinos. Proceso de absorción que supone una confusión, por identificación, entre ambos movimientos sociales urbanos $o$, al menos, la utilización instrumental de las Asociaciones de Vecinos por parte de aquél. En este sentido, creemos que el celebrado crecimiento político de las Asociaciones de Vecinos, asumiendo el protagonismo en el cambio democrático general del Estado español (13) puede explicarse, e incluso justificarse, si atendemos al momento excepcional que supone el tránsito a una democracia después de siete lustros de Estado autoritario. En un período trascendental de la historia de España en el que se extingue una forma de Estado para dar lugar a otra radicalmente distinta, basada en la democracia y en las libertades de un Estado constitucional de Derecho, las consideraciones de técnica científica sobre características de las Asociaciones de Vecinos, sobre si sus actuaciones y fines son propios de

(13) Vid. Borja, J.; Tarrago, M., y BoIX, R.: o. c., pág. 90. 
este tipo de asociación o suponen una extralimitación originante de un movimiento social urbano cualitativamente distinto, deben ceder ante la vida democrática, la libertad cívica y el Derecho. Es esta intuición y la fuerza irresistible del deseo contenido durante largos años, la que ha llevado a las Asociaciones de Vecinos a asumir, juntamente con el movimiento ciudadano, el protagonismo político que comentamos. Protagonismo político que, consolidado el proceso democrático español, creemos debe ser encauzado a través de los partidos políticos. No hacerlo supondría no sólo cerrar los ojos a la Historia, sino también iniciar un proceso de extinción de las Asociaciones de Vecinos.

\section{IdENTIFICACIÓN Positiva dE LAS Asociaciones de Vecinos}

Examinada negativamente la identidad de las Asociaciones de Vecinos y puesto de relieve el peligro de utilización instrumental de las Asociaciones de Vecinos, tanto por la izquierda revolucionaria con su identificación Asociación de Vecinos-poder popular, como por la izquierda no asamblearia centrada en la unión movimiento ciudadano-Asociación de Vecinos, pasamos a analizar nuestra concepción positiva de las Asociaciones de Vecinos.

Reiteradamente hemos expuesto nuestra tesis sobre las Asociaciones de Vecinos como asociaciaciones de defensa del interés vecinal frente a la Administración pública. No es, pues, necesario extendernos de nuevo sobre ella. Baste una remisión a su lectura (14). Unicamente quisiera señalar, muy brevemente, que dicha concepción supone:

a) La configuración básica de las Asociaciones de Vecinos como asociaciones de intereses. En este sentido creemos que, por analogía, la Asociación de Vecinos es un verdadero sindicato vecinal. No es una organización política, que deberá estructurarse a través de los partidos, ni es el poder popular vecinal, que debe estructurarse por medio de la asamblea de barrio o pueblo. Insisto: la Asociación de Vecinos es fundamental y primariamente una asociación de defensa de intereses urbanos.

b) La defensa de estos intereses se realiza frente a la Administración pública, tanto local como estatal. Esta característica, unida

(14) BerRiató $A$, J.: o. c. 
a la peculiaridad del interés vecinal, según pasamos a ver, constituyen la diferencia específica de las Asociaciones de Vecinos dentro del género más amplio de las asociaciones de defensa de intereses.

c) El interés defendido por la Asociación de Vecinos es el interés vecinal. La noción del interés vecinal es un concepto que, no obstante sus reconocidas limitaciones, estimamos como apropiado para definir a las Asociaciones de Vecinos, dada la posibilidad de comprender dentro del mismo, tanto los bienes inmateriales del barrio - de tanta importancia en ocasiones- como la reivindicación de equipamenitos, la participación en el planeamiento urbano y en la gestión y control de los órganos municipales de decisión y gestión, así como las reformas estructurales que lo hagan posible. Generalidad conceptual que constituye su máxima ventaja definitoria y al mismo tiempo su limitación más acusada. Pero, independientemente del valor definitorio del interés vecinal, lo cierto es que, desde el punto de vista material, dicho interés, como su mismo nombre indica, es y debe ser netamente vecinal. Lo que nos cuestiona uno de los puntos más debatidos dentro de la problemática que investigamos: el carácter político o meramente reivindicativo de las Asociaciones de Vecinos. Cuestión que abordamos desde un doble ángulo: el de la Administración pública y el de los partidos políticos.

\section{LAS ASOCIACIONES DE VECINOS Y LA P'OLITICA MUNICIPAL}

1. Su aNÁlisis desde la PERSPECtiva de la AdMiNistración pública

Desde la perspectiva de la Administración, la acusación de politicismo de las Asociaciones de Vecinos, consecuencia de la conflictualidad urbana, se ha convertido en una obsesión que ha enrarecido las relaciones entre estas asociaciones y la Administración pública. Acusación que constituye la causa latente fundamental de denegación de aprobación de las Asociaciones de Vecinos «en trámite" y que se ha convertido en requisito con rango legal en el Real Decreto 713/1977 de 1 de abril.

La constatación de esta acusación nos obliga a enfrentarnos resueltamente con el tema del politicismo de las Asociaciones de 
Vecinos. ¿Son las Asociaciones de Vecinos asociaciones políticas? Si no lo son, ¿hacen de hecho política? ¿Qué clase de política? Interrogantes todas ellas cuya contestación exige la fijación previa de la noción de política municipal (15).

La delimitación conceptual de la política municipal ofrece una dificultad innegable, tanto si intentamos definir el sustantivo la política (16) como si lo pretendido es la definición del adjetivo política municipal (17). Por ello, y dado que la cuestión definitoria tiene interés, a nuestros efectos tan sólo en cuanto puede ayudarnos a fijar el contenido político de las Asociaciones de Vecinos, abordamos el tema sin pretensión alguna de agotarlo, antes bien esbozando simplemente unas líneas de reflexión sobre una problemática que sería mi deseo abordar en profundidad en un futuro. En este sentido podemos insinuar las siguientes reflexiones:

Primera. Prescindiendo de la imposibilidad de aplicar al campo municipal, y por ende al de las Asociaciones de Vecinos, la discutida doctrina administrativa sobre el acto político (18), creemos que el primer sentido de la política a aclarar es el etimológico, esto es, el de la política como participación de los ciudadanos en los problemas de la polis. Sentido primigenio de indudable importancia de cara a las Asociaciones de Vecinos.

A este respecto, es indudable que la ciudad actual tiene un sen-

(15) La necesidad de precisar el concepto de política municipal fue inmediatamente sentida cuando en el Seminario de Investigación sobre "Desarrollo comunitario urbano: especial referencia a distritos y barrios», organizado por el Instituto de Estudios de Administración Local, surgió la problemática de la incidencia de las Asociaciones de Vecinos en la vida municipal.

(16) Vid. SÁnchez AGESTA, L.: Lecciones de Derecho político, I, Granada, 1943, y Principios de teoria politica, Madrid, 1967. SchmIT, C.: Begriff der Polischen, Berlín. 1927. Traducción española de F. J. Conde, Instituto de Estudios Políticos, Madrid, 1941. FraGa IrIBarne, M.: La crisis del Estado, Madrid, 1958. La misma noción de poder, como elemento central de lo político, ofrece indudables dificultades. En este sentido, puede verse Blanco ANDE, J.: Teoría del poder, Madrid, 1977.

(17) Esta noción está intimamente vinculada con la idea del pouvoir municipal, cuya existencia y contenido ha sido ya desmitificado por la doctrina. En este sentido AlBI, F.: La crisis del municipalismo, Madrid, 1966. GARCfa DE ENTERRfa, E.: "Los fundamentos ideológicos del sistema municipal francés», en REvisTa DE EsTUDIOS DE LA VIDA LOCAL, 117 (1961), págs. 321 y ss., y «Administración periférica del Estado y Administración local: problemas de articulación», en Problemas Políticos de la Vida Local, I, Madrid, 1961, págs. 227-270. SAlas HeRnANDeZ, J.: aEl tema de las competencias: instrumentación de las relaciones entre el Estado y la Administración local desde la perspectiva de la descentralización territorial», en la obra colectiva Descentralización administrativa y organización política, por MARTín RETORTILlo, S., y otros, tomo III, págs. 303 y ss.

(18) Vid. BOouera OlIVER, J. M.: Derecho administrativo, Madrid, 1972, pág. 107 y la bibliografía citada por el mismo. 
tido político y una organización radicalmente distinta de la ciudadEstado, propia de la Atenas de Platón y ARistóteles. Pero si por traslación entendemos por política la participación de los ciudadanos en la solución de los problemas de su ciudad, creemos que en este sentido la política municipal es la política por excelencia y que las Asociaciones de Vecinos son asociaciones que pueden y deben hacer política. La defensa del interés vecinal implica indudablemente una participación en toda la problemática urbana relativa a equipamientos colectivos, planificación y gestión de la ciudad, cuyo significado político, en el sentido que comentamos, no ofrece duda alguna. Según la acepción etimológica del término, las Asociaciones de Vecinos son, pues, asociaciones políticas.

Segunda. En un segundo sentido creemos que tampoco ofrece dudas el politicismo de las Asociaciones de Vecinos. Nos referimos a la labor de concienciación política de cara a la asociación y al vecindario en general realizada por las Asociaciones de Vecinos. Concienciación política que puede ser de integración (19), pero que en la generalidad de los casos es de ruptura ideológica con el capitalismo urbano. Esta labor de concienciación, unánimemente admitida por tratadistas y líderes vecinales (20), implica una crítica del capitalismo urbano, como causa originante de la situación de las barriadas populares, y la defensa del modelo socialista como solución unica de la problemática vecinal. Crítica y defensa de los modelos urbanos realizada habitualmente por las Asociaciones de Vecinos y cuyo alcance político es innegable.

Tercera. Creemos que en un tercer sentido las Asociaciones de Vecinos son también políticas. Nos referimos al carácter político de las Asociaciones de Vecinos como poder social. En este aspecto, las Asociaciones de Vecinos, creemos, sin necesidad de llegar a ser consideradas como la exteriorización organizada del poder popular, frente a la Administración, sino simplemente como entes

(19) Creemos que no existe razón intrínseca alguna para que una Asociación de Vecinos realice una labor de concienciación del vecindario propugnando la aceptación del vigente sistema urbano y la colaboración con la Administración pública.

(20) Angulo, J.: Cuando los vecinos se unen, Madrid, 1972, págs. 133 y ss. BERRIATÚA, J.: o. C., págs. 211-212 y 288-290. BorJa, J.: Qué son las Asociaciones de Vecinos, Barcelona, 1976, pág. 19. Eouipos de BASE. Barcelona: «Los barrios y el poder popular», en Teoría y Práctica, 5 (1977), pág. 51. OMEÑACA, J.: o. c., páginas 77-78. 
reivindicativos y de defensa de intereses vecinales, constituyen, sin duda alguna, una fuerza social cuyo poder político no puede ignorarse.

Cuarta. También son políticas, con las debidas matizaciones, las Asociaciones de Vecinos si por política entendemos el hecho de que los Municipios forman parte de la organización del Estado. Este carácter político del Municipio es indudable (21); ahora bien, bajo este ángulo, ¿en qué sentido son políticas las Asociaciones de Vecinos?

En la organización corporativista del Estado del 18 de julio, cuya normativa sigue vigente aún, las posibilidades políticas de las Asociaciones de Vecinos podían y debían encauzarse a través del derecho de las Asociaciones de Vecinos a participar directamente en la elección de candidatos municipales del tercio de entidades. Creemos, y así lo afirmamos anteriormente (22), que las Asociaciones de Vecinos, como asociaciones de defensa del interés vecinal, debían ser las asociaciones tipo con derecho a elegir concejales municipales por el tercio de entidades. El carácter político, por ende, de las Asociaciones de Vecinos debe ser reconocido mientras no se derogue dicha normativa legal.

Mayores dudas ofrece el supuesto de que el proceso democrático suponga la abolición del sistema corporativista y su sustitución por un sisteema de representación directa. En este supuesto, para OMEÑACA, la labor política de las Asociaciones de Vecinos es innegable: "Las asociaciones no es que deban politizarse o no; es que se han de politizar, aunque no se quiera... Cuando vemos que los Ayuntamientos son parte del Estado y que, como tales, no responden a los intereses populares, sino a los intereses del gran capital (no olvidemos la esencia democrático-burguesa del Estado democrático actual), inmediatamente planteamos la necesidad de unos

(21) Garcfa-Trevijano, J. A.: aArticulación Estado-entes locales», en Revista dE Estudios dE LA Vida Local, 153 (1967), págs. 321-344. GarRido Falla, F.: «Evolución y problemática de las relaciones entre el Estado y la Administración local», en Problemas Politicos de la Vida Local, VII, 1967, págs. 255-313. Herrero TejeDOR, F.: "Aspectos políticos de la Vida local», en Problemas Políticos de la Vida Local, VI, 1966, págs. 347-375. MARTfN-Retortillo BAQUeR, S.: «Presupuestos políticos de la Vida local», en Revista de Administración Pública, 43 (1964), págs. 9-35, y en Problemas Políticos de la Vida Local, IV, 1964, págs. 147-181. RUIZ DEL. CASTILLO: «La inserción de la Vida local en el Estado», en REVISTA DE Estudios DE LA VIDA LoCAL, 7 (1943), págs. 31-49.

(22) BerRiatúa, J.: o. c., págs. 215-218. 
Ayuntamientos democráticos. Estamos exigiendo que el pueblo tenga acceso a una esfera del poder político" (23).

La argumentación no carece de fuerza. Reconocida la importancia básica del Municipio en la organización política del Estado es indudable que cualquier alteración en la situación de las fuerzas políticas del Municipio supone una alteración que repercute en el balance general de las fuerzas políticas a nivel estatal. Y ello porque, si el Municipio es parte de la organización del Estado, cualquier alteración política a nivel de Municipio supone también una alteración política a nivel estatal. De ahí la importancia, indudablemente política, de las Asociaciones de Vecinos a nivel municipal y estatal (24).

Sin embargo, hemos de matizar esta importancia política de las Asociaciones de Vecinos. Creemos que su carácter político, en el sentido que analizamos, no deviene tanto de la institucionalización de estas asociaciones como de las repercusiones de su actividad. Institucionalmente, el carácter político de las Asociaciones de Vecinos vendrá reconocido cuando se establezca legalmente y de forma explícita la participación de las Asociaciones de Vecinos en el gobierno de su ámbito vecinal. Pero mientras dicha institucionalización no se realice, el politicismo de las Asociaciones de Vecinos, en el sentido analizado, tendrá lugar extra legem a través de la importancia decisiva de las Asociaciones de Vecinos como fuerza social y del peso decisivo que las mismas puedan tener de cara a unas elecciones municipales.

Quinta. Mayores dudas ofrece, en cambio, el carácter político de las Asociaciones de Vecinos si por política entendemos la realización en la ciudad del indirizzo político (25). Si por traslación aplicamos esta noción al campo municipal, la adopción de las resoluciones que implica el ejercicio del indirizzo político correspon-

(23) OMEÑaCA, J.: o. c., pág. 111.

(24) Vid. BorJa, J.; Tarrago, M., y Borx. R.: o. c., págs. 105 y ss.

(25) Sobre el indirizzo político, escribe PEREZ DoBLÓN, J. J. - «Articulación democrática y entes locales», en REDA, 9 (1976), pág. 274-: «Han tenido lugar, y lo tendrán en el futuro, vivas controversias en todo aquello que hace referencia al concepto, elementos, función, relevancia y titularidad. Por tal podría hablarse de "dirección política", de "determinación de la política general estatal", o, incluso, con términos empleados por el artículo 13 de la LOE, en su párrafo 11, de "determinación de la política nacional". En realidad, lo importante es aclarar que en sustancia el así llamado indirizzo político equivale a la determinación de las finalidades prioritarias a que todos los organismos del Estado han de orientar su actividad en un determinado momento históricos. 
de, a nuestro entender, a los órganos legales del Municipio, y el rol de las Asociaciones de Vecinos ha de ser puramente de carácter indirecto a través de información, control y cooperación, conflictiva o no. Pero la realización de la política municipal, como adopción de decisiones entre una pluralidad lícita de las mismas, es propia de la Administración local y de sus órganos de decisión. Las Asociaciones de Vecinos, como entes de Derecho privado, cooperarán, siendo deseable la institucionalización de dicha cooperación, con la Administración pública. Pero su función es puramente de colaboración y no de decisión. En la acepción indicada de la política, como adopción de las medidas propias del indirizzo político, las Asociaciones de Vecinos no son políticas ni deben serlo.

Sexta. Terminamos este breve resumen del carácter político de las Asociaciones de Vecinos señalando cómo la defensa del interés vecinal frente a la Administración, fin social de estas asociaciones, comprende no sólo la defensa del conjunto de bienes materiales a inmateriales necesarios para una vida urbana digna, sino también la reivindicación de cuantas reformas legislativas e instrumentos jurídicos sean necesarios para el ejercicio de aquella función reivindicativa.

De las consideraciones expuestas podemos deducir que, a nuestro juicio, las Asociaciones de Vecinos no son asociaciones políticas, sino meramente reivindicativas y defensoras del interés vecinal frente a la Administración. Esta afirmación no es obstáculo para reconocer que, sin perder este carácter esencialmente reivindicativo, las Asociaciones de Vecinos pueden realizar actividades que, según la acepción corriente del lenguaje, se denominan políticas. En este sentido, estimamos que: las Asociaciones de Vecinos se preocupan hondamente de la problemática urbana y de la con. cienciación vecinal; suponen una fuerza social de indudable peso; no son fuerzas con poder decisorio, pero sí tienen un peso específico en el juego político de las fuerzas municipales, y de ahí su importancia tanto a nivel municipal como estatal. Por último, intervienen en la política legislativa, solicitando las reformas legales necesarias para el ejercicio de sus funciones.

Desde el ángulo de la Administración pública, las Asociaciones de Vecinos son, según hemos visto, asociaciones esencialmente de defensa de intereses vecinales. Carácter reivindicativo y de defensa de intereses vecinales, que subsiste íntegramente, no obstante los 
aspectos políticos que hemos analizado. Dichos aspectos podrán tener un interés sociológico o político, pero desde el punto de vista jurídico son indiferentes. Desde el punto de vista del Derecho, una Asociación de Vecinos que defienda el interés vecinal, aun cuando con dicha defensa pueda incurrir conjuntamente en alguna de las repercusiones políticas estudiadas, obra jurídicamente dentro de los límites de su fin social. No existe extralimitación. Obra, por ende, dentro del marco legalmente permitido. Por ello, y dada la sumisión de la Administración pública al principio de legalidad, ésta debe respetar la vida y existencia de la asociación.

\section{SU ANÁLISIS DESDE LA PERSPECTIVA DE LOS PARTIDOS POLfTICOS}

Si las relaciones Administración pública-Asociación de Vecinos deben regirse por el principio de legalidad de la Administración, las de las Asociaciones de Vecinos-partidos políticos son extrajurídicas. Su interés a los efectos de investigar la posición de las Asociaciones de Vecinos en el proceso democrático español es decisivo. Entramos, pues, en su análisis.

Ya hemos puesto de relieve anteriormente la existencia de un conflicto latente entre las Asociaciones de Vecinos y los partidos políticos por el dominio del poder vecinal. Conflicto que aflora en el intento de utilización instrumental de aquéllas. En este punto es curioso observar cómo, no obstante la afirmación general de tratadistas y líderes vecinales (26) sobre la distinción e independencia entre Asociaciones de Vecinos y partidos políticos, lo cierto es que la injerencia es continua, y de no ponerle fin puede dar lugar en un futuro próximo a la extinción misma de estas asociaciones vecinales. El tema es lo suficientemente grave como para que justifiquemos nuestra afirmación.

Entendemos que la extralimitación continua de fines sociales y la inmersión de las Asociaciones de Vecinos, bien sea en el movimiento asambleario, bien en el ciudadano, asumiendo las finalidades más amplias de dichos movimientos, son una muestra de la intromisión de los partidos en la vida de las Asociaciones de Vecinos y del intento de su utilización instrumental. Pero no es la única. Podemos, además, señalar las siguientes:

(26) BorJa, J.; Tarrago, M., y Borx R.: o. c., pág. 36. Omeñaca, J.: o. c., páginas 97 y ss. Chicharro, M.: aLa crisis de la Federación de Vecinos», en El País, 27 de noviembre de 1977, pág. 16. 
a) La subordinación de las Asociaciones de Vecinos a un partido político puede realizarse mediante la simple inactividad de los líderes vecinales. No hay duda de que, juntamente con algún independiente, los líderes vecinales miembros de las Juntas directivas de las Asociaciones de Vecinos están encuadrados ordinariamente en alguna organización política. En el caso de que la actividad de la asociación vecinal no coincida con los planteamientos tácticos de la organización $\mathrm{u}$ organizaciones políticas de los miembros de la Junta, bastará simplemente que éstos adopten una actitud de inactividad para que la Asociación de Vecinos se introduzca en vía muerta. Esta afirmación pudimos comprobarla cuando en los momentos históricos de la transición política del Estado español hacia la democracia parecía que las Asociaciones de Vecinos habían con. seguido todas sus reivindicaciones urbanas, ya que estuvieron prácticamente inactivas durante una larga temporada. Es una forma tácita y sutil de utilización instrumental. Realizar la actividad de una Asociación de Vecinos cuando coincida con los planteamientos de su partido político o, en caso contrario, inhibirse y paralizar la vida asociativa.

Análogos efectos observamos cuando por motivos de reestructuración del partido o de formación de sus cuadros, los líderes vecinales, encuadrados en organizaciones políticas, descuidan totalmente la actividad de una Asociación de Vecinos.

b) Una segunda forma es la de proponer a la Asociación de Vecinos y a los vecinos como acción a realizar aquella que la organización política del líder vecinal ha determinado previamente. Las consecuencias de esta intromisión son, sencillamente, que la Asociación de Vecinos al asumir como propios los planteamientos vecinales de una determinado partido político, viene a potenciar políticamente a dicho partido, el cual no sólo aprovecha las masas vecinales de la asociación, sino también prestigia su programa político dada su adhesión a nivel vecinal (27).

c) En tercer lugar y cuando el partido político no pueda conseguir la subordinación de la Asociación de Vecinos por los medios anteriormente señalados, la técnica utilizada es distinta. El partido político crea una nueva Asociación de Vecinos en el barrio. Aso-

(27) Tal ocurrió, según OMEÑACA, con la propuesta por algunas Asociaciones de Vecinos del Gran Bilbao en la propuesta del Metro popular. Vid. OmeÑaCA, J.: obra citada, págs. 104 y ss. 
ciación vecinal totalmente dominada por dicho partido y correa de transmisión a nivel vecinal de sus consignas (28).

Estas formas de utilización instrumental y cualesquiera otras que puedan producirse, independientemente de suponer la iniciación de un proceso de extinción de las Asociaciones de Vecinos, responde en último término a una plena lógica política. Por encima de disquisiciones jurídicas, los partidos políticos utilizan cuantos medios están a su alcance, incluidas las Asociaciones de Vecinos, para potenciar a sus organizaciones y alcanzar el poder. Cualquier consideración de tecnicismo jurídico o sociológico debe, a su juicio, subordinarse a la política. De ahí que las Asociaciones de Vecinos no sean una excepción. Estas deben encuadrarse dentro de planteamientos políticos más generales.

\section{EXAMEN DE LOS FACTORES DETERMINANTES}

En un intento de explicar los mecanismos reseñados, creemos que, en último término, las diversas relaciones posibles entre las Asociaciones de Vecinos y los partidos políticos dependen del juego de los siguientes factores determinantes:

1. La opción entre capitalismo y socialismo.

2. La legalidad o ilegalidad de los medios de acción.

3. Las alianzas tácticas.

4. La titularidad del poder vecinal (asamblea versus conce. jales).

5. La institucionalización de la vía asamblearia o electoralista.

El primer factor determinante señalado es el de la opción entre capitalismo y socialismo. Según esta variable, pueden existir dos tipos de Asociaciones de Vecinos: a) Las Asociaciones de Vecinos que admitan como modo de producción el sistema capitalista en cualquiera de sus dos variedades: liberal o socialdemócrata. b) Asociaciones de Vecinos que, rechazando dicho sistema, se inclinen por el anarquismo libertario o por el socialismo democrático o marxista.

El segundo factor tiene en cuenta la legalidad o ilegalidad de

(28) OMEÑaCA, J.: o. c., pág. 104. 
los medios de acción de las Asociaciones de Vecinos. Ilegalidad que comprende no sólo el supuesto extremo del uso continuo y consciente de la ilegalidad revolucionaria, sino también las formas más sutiles de a-legalidad. A este respecto señalamos la posible presencia de Asociaciones de Vecinos cuyos lideres sostengan que debe utilizarse la legalidad de medios cuando interese a los fines perseguidos, pero debe prescindirse de aquélla cuando sea un obstáculo a la reivindicación o las finalidades políticas pérseguidas por la Asociación de Vecinos.

Para el tercer factor determinante, las alianzas tácticas de una Asociación de Vecinos pueden ir desde la negación total a alianzas que vayan contra el capitalismo urbano legalmente vigente hasta: a) Mantener su independencia reivindicativa como Asociación de Vecinos, no obstante su oposición al capitalismo urbano. b) Admitir su alianza con otras fuerzas de la oposición al sistema capitalista, pero dentro de un planteamiento interclasista. c) Admitir la alianza de las Asociaciones de Vecinos únicamente con aquellas organizaciones de ruptura revolucionaria.

Para el cuarto factor determinante, lo decisorio es la determinación de quién es el titular del poder vecinal. Es indudable que, en último término, el ciudadano es el titular de la voluntad general. Pero este reconocimiento no es obstáculo para que la voluntad popular del ciudadano pueda instrumentalizarse técnicamente de formas diferentes. Más en concreto, admitida la voluntad del vecino como legitimación política a nivel urbano, aquélla puede manifestarse y organizarse en la asamblea de barrio o pueblo, o, por el contrario, a través de la elección de representantes legales, los cuales, en virtud de la representación obtenida, son el supremo órgano de poder urbano.

Este factor supone una opción entre el sistema asambleario y el electoralista como formas de legitimación política. Opción que es enormemente importante para comprender el funcionamiento de algunas Asociaciones de Vecinos. Admitida la asamblea como supremo poder político de la ciudad, a ella deben subordinarse tanto las Asociaciones de Vecinos como los representantes municipales legalmente elegidos. La asamblea, como supremo órgano de poder vecinal, es la máxima autoridad a la cual deben subordinarse tanto las Asociaciones de Vecinos como todos los órganos legales del Municipio. Por el contrario, la admisión de la vía electoralista im- 
plica que la voluntad del pueblo se manifiesta a través de unas elecciones municipales y que los representantes así elegidos son la expresión de la voluntad popular y el supremo órgano de gobierno municipal. En último término, se trata de elegir entre una democracia directa o indirecta. Sus repercusiones de cara a la institucionalización de las Asociaciones de Vecinos es decisiva, según pasamos a ver en el análisis del último factor determinante.

El último factor determinante reseñado es el de la institucionalización de la vía electoralista o de la vía asamblearia. El rol de las Asociaciones de Vecinos es radicalmente distinto en uno y otro sistema.

En el sistema asambleario, la asamblea de pueblo o barrio, como supremo órgano de poder popular, supedita a ella la totalidad de plataformas políticas de actuación, las Asociaciones de Vecinos y los representantes legalmente elegidos. Para dicho sistema, la Asociación de Vecinos es un elemento más a incardinarse en el movimiento asambleario y en la asamblea de barrio o pueblo como órgano de expresión del poder popular. La Asociación de Vecinos queda convertida en una pieza más del asambleísmo, supeditada a la voluntad asamblearia. Su naturaleza, esencialmente reivindicativa, queda desnaturalizada por desbordamiento. La Asociación de Vecinos, en última instancia, es una organización revolucionaria que, defendierdo los intereses vecinales, se inserta, como un elemento más, en los planteamientos políticos de la izquierda revolucionaria asambleísta.

La aceptación, por el contrario, de la vía electoralista implica para las Asociaciones de Vecinos que el poder político a nivel municipal se organiza a través de los partidos políticos y de la elección de representantes municipales. Las Asociaciones de Vecinos en este juego democrático electoralista se reducen, en síntesis, a: 1) Aceptar su utilización instrumental por las organizaciones políticas, convirtiéndose en sindicatos vecinales al servicio de los partidos políticos, de sus tácticas y de la promoción electoral de sus representantes, o 2) Huir de toda utilización instrumental, reivindicando su independencia tanto de la Administración pública como de los partidos políticos y convirtiéndose en lo que exige su propia naturaleza de Asociación de Vecinos, esto es, en asociaciones que defienden el interés vecinal frente a la Administración pública, cualquiera que sean los resultados electorales posibles de su Mu- 
nicipio. En este supuesto, frente al juego dualista partidos políticos-concejales municipales, las Asociaciones de Vecinos, conservando su independencia, serían verdaderas Asociaciones de Vecinos.

\section{Tipología polftica de las asociaciones de Vecinos}

Llegados a esta fase de nuestra reflexión, sería de un enorme interés poder comprobar el juego de los factores determinantes examinando las alternativas municipales y los planeamientos vecinales de las distintas organizaciones políticas. Su análisis desborda nuestras posibilidades. Por ello, aunque toda tipología es incompleta y no se halla nunca en estado de pura naturaleza, creemos que las perspectivas futuras del asociacionismo vecinal pueden ofrecer tres tipos básicos de Asociaciones de Vecinos.

1. ${ }^{\circ}$ Las Asociaciones de Vecinos del capitalismo democrático. Dichas asociaciones centran su vida, fundamentalmente, en los factores de: la aceptación del capitalismo, la legalidad de medios de acción, las no alianzas con fuerzas políticas o vecinales de oposición revolucionaria, en la aceptación del sistema electoralista y en la afirmación de que el poder vecinal reside, por ende, en los concejales democráticamente elegidos en unas elecciones municipales. Dichas Asociaciones de Vecinos, como entidades de reivindicación vecinal, serían asimismo partidarias de institucionalizar la cooperación con la Administración pública mediante el establecimiento de los oportunos cauces e instrumentos legales de cooperación.

2. Las Asociaciones de Vecinos de la oposición democrática. Dichas asociaciones centran su vida, fundamentalmente, en los factores de: su opción por el socialismo, la legalidad ordinaria de los medios de acción, de las alianzas tácticas con cuantos partidos, asociaciones ciudadanas y organismos profesionales adopten una postura de oposición democrática, son partidarias de la vía electoralista y de que, por ende, el poder vecinal resida en los concejales legalmente elegidos en las elecciones municipales. Para esta tipología, las Asociaciones de Vecinos son distintas de los partidos políticos, pero debe favorecerse todo cuanto sea favorable para su incardinación en movimientos masivos de tipo ciudadano. Por lo demás, y reconociendo, asimismo, la independencia de las Asociaciones de Vecinos y los concejales electos, podrían admitir gusto- 
sas una institucionalización jurídica de su cooperación con la Administración local.

3. Las Asociaciones de Vecinos de la oposición revolucionaria. Para esta tipología, las Asociaciones de Vecinos deben centrarse en los siguientes factores: oposición al capitalismo, legalidad o ilegalidad de los medios de acción, alianzas tácticas con aquellos partidos, plataformas y organizaciones revolucionarias de ruptura, titularidad del poder vecinal en la asamblea de barrio o pueblo y rechazo, por ende, de la vía electoralista o admisión de la misma como mero recurso táctico y con la sumisión expresa de los concejales elegidos a la voluntad popular manifestada en la asamblea de barrio o pueblo. Este tipo de asociacionismo vecinal podría $r \epsilon$ chazar, como contrarrevolucionaria, la institucionalización de la cooperación de las Asociaciones de Vecinos con la Administración pública.

Las tipologías mencionadas tienen un carácter meramente indicativo. Pero creemos que responden a tres líneas. básicas de actuación. Actuación que, por encima de construcciones meramente doctrinales, vendrá determinada por la fuerza real de los partidos políticos y de los líderes vecinales que actúan en los barrios y distritos urbanos. Según sea su fuerza real, triunfará una u otra línea, con las repercusiones que ello acarreará de cara a los vecinos y a la vida misma de las Asociaciones de Vecinos. El tiempo y la historia nos dirá si asistimos o no a la indicación de un auténtico proceso de extinción de las Asociaciones de Vecinos.

\section{EL RETO DE LA INSTITUCIONALIZACION JURIDICA}

Si la injerencia de los partidos políticos puede llegar a cuestionar la identidad de las Asociaciones de Vecinos, la institucionalización jurídica de la participación vecinal en el gobierno del barrio o distrito puede suponer un vaciamiento funcional que cuestione la necesidad misma de las Asociaciones de Vecinos. Nos referimos no a la generalización en el espacio y tiempo de las formas de control de los Ayuntamientos en el período preelectoral español, ni tampoco a la posible y deseada regulación jurídica de la participación de las Asociaciones de Vecinos en el gobierno municipal mediante la regulación de sus facultades de información, vigilancia y 
control, sino a la participación del vecindario en el gobierno de su unidad vecinal mediante fórmulas de descentralización municipal. Descentralización municipal que supone el reconocimiento explícito del barrio o distrito como circunscripción de gobierno municipal y la elección por los vecinos de los órganos de gobierno de dichas circunscripciones. Fórmulas de descentralización suburbana, cuyo modelo más importante encontramos en la Ley italiana de 18 de abril de 1976.

Joaquín ToRNos (29), en un artículo cuya importancia desborda el marco de una mera crónica administrativa, recoge no sólo el texto de la Ley italiana de 18 de abril de 1976, sino también la compleja problemática que subyace en todo intento de buscar nuevas fórmulas jurídicas de organización municipal. Por nuestra parte, nos limitaremos a señalar las repercusiones que una posible implantación del modelo italiano en el Estado español puede suponer en orden a la vida futura de las Asociaciones de Vecinos.

Siguiendo a ToRnos (30) podemos señalar que el marco legal dentro del que se desenvolvía la vida de los Municipios italianos era la Ley Municipal y Provincial de 1915, que en su artículo 155 hacía referencia al problema de la descentralización municipal. Concretamente, dicho artículo establece que los Municipios de más de 60.000 habitantes pueden decidir su división en barrios, en cuyo caso el Alcalde podrá nombrar delegados o colaboradores para ejercer las funciones que él ostenta como delegado del Gobierno. Se establecía así de forma escueta y ambigua una posible desconcentración para los Municipios mayores de 60.000 habitantes. A la sombra de dicha normativa y del espíritu descentralizador de los artículos 5..$^{\circ}$ y 128 de la vigente Constitución italiana surgen, en el período 1960-75, la conflictualidad urbana, la ideología del barrio y el asociacionismo vecinal.

En un primer momento, como superación de la fase en la que sólo existían asociaciones espontáneas de base y siguiendo el modelo del Municipio de Bolonia, la descentralización municipal se basó en los puntos siguientes:

a) Creación de barrios en zonas urbanísticas homogéneas y en general autosuficientes desde el punto de vista de servicios públicos.

(29) ToRnos MAS, J.: aCentralización municipal y participación ciudadana en Italia", en Revista de Administración Pública, 81 (1976), págs. 371-394.

(30) TORNos Mas, J.: o. c., págs. 372-375. 
b) El Consejo de Barrio, órgano principal, compuestos por los ciudadanos del barrio elegidos por los partidos políticos en número proporcional a la composición del Consejo municipal.

c) Las funciones ejercidas por el barrio son exclusivamente consultivas y de propuesta, siendo diversos los criterios para determinar qué materias son competencia de aquél.

A partir de este esquema se inicia un proceso evolutivo en el que se aumentan las competencias del barrio, las consultas obligatorias al mismo y la elección por sufragio universal de los Consejos de Barrio. Proceso que culmina en la Ley de 18 de abril de 1976. La descentralización municipal en la Ley italiana de abril de 1976 se basa en los siguientes elementos básicos:

1. El reconocimiento del barrio (31) como unidad territorial de gobierno municipal (32).

2. ${ }^{\circ}$ La implantación como órganos del barrio: a) el Consejo de Barrio, y $b$ ) el Presidente del Consejo de Barrio (33).

3. En orden a la elección y competencias del Consejo de Barrio se adopta una solución de compromiso en base a reconocer dos fórmulas distintas de Consejo de Barrio:

a) El Consejo de Barrio con elección directa y competencias consultivas y decisorias (34).

(31) Siguiendo a ToRnos -o. c., pág. 380, nota 15- traducimos el término italiano de circoscrizione por el de barrio.

(32) En este sentido, el artículo $10^{\circ}$ de la Ley italiana de 18 de abril de 1976 establece que: "Hasta la entrada en vigor de una nueva regulación de las autonomías locales, con el fin de promover la participación popular en la gestión administrativa de las comunidades locales y como desarrollo del principio de autonomía sancionado en el artículo 128 de la Constitución, los Municipios podrán dividir su territorio en circunscripciones, que comprendan uno o más barrios o zonas contiguas, ejercitando el poder de organización dentro de una amplia descentralización».

(33) La mencionada Ley italiana, en su artículo $2 .^{\circ}$, establece que: "Serán órganos del barrio: a) El Consejo de Barrio. b) El Presidente del Corisejo de Barrio.

El Consejo de Barrio representa los intereses de la población de su demarcación en el ámbito de la unidad del Municipio. Las reuniones del Consejo de Barrio serán públicas.

El Presidente del Consejo de Barrio representa al Consejo y desempeña las funciones que le delegue el Alcalde, incluidas las que éste ostente como delegado del Gobierno».

(34) En este sentido, el artículo $3 .^{\circ}$, párrafos $10^{\circ}$ y $2 .^{\circ}$, determina que: «Los Consejos de Barrio serán elegidos por sufragio directo en los Municipios que hayan otorgado a estos Consejos los poderes consultivos y decisorios previstos en los artículos 12 y 13 y que tengan una población no inferior a 40.000 habitantes.

Independientemente del número de habitantes del Municipio, los Consejos de 
b) El Consejo de Barrio con elección indirecta y facultades meramente consultivas (35).

Del examen del modelo legal italiano podemos apreciar cómo el artículo 12, y con carácter general para todo tipo de Consejo de Barrio, impone como obligatorio el informe preceptivo, pero no vinculante, del Consejo de Barrio en materias tan importantes como el presupuesto municipal, la gestión de servicios, la planificación urbana y la redacción de las ordenanzas municipales. Además, se le reconoce la facultad de propuesta en materia de determinados servicios (sanitario, asistencial, escolar, deportivo, recreativo) y, en general, en todo lo relativo a la problemática de su demarcación. Tiene, asimismo, facultades de exponer su parecer en todas las materias de competencia del Consejo municipal. Y se le reconoce la facultad de convocar, de acuerdo con las ordenanzas municipales, asambleas con objeto de someter a discusión pública los problemas inherentes a la demarcación.

Juntamente con estas facultades consultivas, reconocidas en este artículo para todo tipo de Consejo de Barrio, el artículo 13 de la

Barrio podrán ser elegidos por sufragio directo si las ordenanzas municipales asi lo prevén y siempre que les sean otorgados los poderes mencionados en el párrafo anterior".

Por su parte, el artículo 12 determina que: "El Consejo de Barrio:

a) Emitirá su parecer y formulará propuestas en orden al funcionamiento de los órganos descentralizados y a la gestión de los bienes, servicios a instituciones municipales de carácter sanitario, asistencial, cultural, escolar, deportivo y recreativo y de cualquier otro orden, existentes en la circunscripción.

b) Podrá convocar, de acuerdo con las ordenanzas municipales, asambleas con objeto de someter a ciscusión pública los problemas inherentes a la demarcación.

c) Podrá formular propuestas para la resolución de los problemas propios de la demarcación correspondiente.

d) Expresará su parecer, bajo su propia iniciativa o a solicitud de la Corporación municipal, en las materias de competencia del Consejo municipal.

Las ordenanzas municipales determinarán las materias en relación con las suales el informe será preceptivo, siéndolo en todo caso:

1) En lo que se refiere al proyecto de presupuesto aprobado por la Junta municipal y los planes plurianuales de inversión y gastos que vinculan el presupuesto por más de cinco años.

2) En lo relativo a los criterios generales de establecimiento y gestión de los servicios, así como en el tema de las directrices principales de la distintas materias y sectores de actividad.

3) En lo concerniente al Plan General de Ordenación urbana, Planes parciales y Proyectos de urbanización y demás acuerdos en materia urbanística, especialmente los relativos a urbanización y emplazamiento de edificios destinados a equipamientos que afecten a la circunscripción".

(35) El artículo $39^{\circ}$ 3, señala que: "Aquellos Consejos de Barrio a los que al Municipio haya otorgado sólo los poderes consultivos previstos en el artículo 12, serán elegidos por el Consejo municipal, según lo establecido en el artículo siguiente». 
Ley que analizamos reconoce también al Consejo de Barrio elegido por sufragio universal una serie de facultades decisorias en materias relativas a obras públicas y servicios municipales.

Creemos que la importancia de la normativa descrita es decisiva para la vida de las Asociaciones de Vecinos, y que un trasplante de la misma al ordenamiento jurídico español puede suponer para este tipo de asociaciones vecinales la iniciación de un proceso de extinción o tal vez, y aunque parezca que resulte paradójico, la recuperación de su propia identidad.

La institucionalización de la gestión de los intereses vecinales o de distrito a través de estas fórmulas de descentralización municipal, puede suponer para las Asociaciones de Vecinos un vaciamiento de competencias que haga inútil su existencia como asociaciones de defensa del interés vecinal frente a la Administración. Dicha defensa es asumida, asimilada, por la propia Administración pública. Ella es la que oye directamente al vecindario, ella es la que encuadra en su seno a los representantes elegidos por el barrio, ella es la que resuelve los conflictos de interés entre el barrio y la ciudad. Así, a través de la institucionalización de la voluntad vecinal mediante los Consejos de Barrio, la Administración digiere la conflictualidad urbana y somete a la legalidad municipal los movimientos vecinales de oposición. Y todo ello en nombre de la democracia.

\section{REFLEXION FINAL}

Podemos concluir nuestra investigación con una reflexión final. Del análisis realizado podemos deducir que, juntamente con el primer peligro de utilización instrumental de las Asociaciones de Vecinos por parte de los partidos políticos, aparece un segundo, tal vez más decisivo para el futuro de las Asociaciones de Vecinos. Peligro real si se institucionaliza en España el modelo italiano u otro análogo y los vecindarios de nuestras ciudades industriales estiman que a través de los nuevos cauces legales pueden defender y satisfacer más provechosamente los intereses vecinales.

En ambos aspecto, el político y el institucional, es imposible hacer predicciones. Lo que sí creemos es que la importancia de los intereses en juego da lugar a que, tanto Ios partidos políticos como la misma Administración pública, intentan e intentarán atraer a su 
campo de acción a las Asociaciones de Vecinos utilizándolas instrumentalmente o vaciando su contenido funcional. Son factores extrajurídicos los que decidirán el futuro de estas Asociaciones. Lo que sí podemos afirmar es que si las Asociaciones de Vecinos no recuperan y defienden su propia identidad como asociaciones de defensa del interés vecinal frente a la Administración, asistimos ya al inicio de su proceso de extinción. El futuro tiene la palabra. 